\title{
A HETERONÍMIA DE FERNANDO PESSOA: LITERATURA PLURILÍNGUE E TRANSLACIONAL
}

\author{
Joachim Michael ${ }^{*}$ \\ Universidade de Bielefeld
}

\begin{abstract}
Resumo: Fernando Pessoa é um dos poetas portugueses mais importantes, mas ele também foi um grande poeta inglês. Partindo desta observação, o presente artigo propõe-se a discutir a função das línguas, de suas diferenças e das passagens interlinguísticas na obra de Pessoa. Esta questão levanta o problema da escrita heteronímica, já que alguns heterônimos eram estrangeiros e escreviam em inglês e em francês, outros eram portugueses e escreviam em português, uns traduziam para o inglês, outros traduziam para o português, uns divulgavam obras estrangeiras ensaisticamente em Portugal, outros faziam o mesmo na Inglaterra. Nota-se, portanto, que a heteronímia encontra na transgressão dos limites linguísticos e culturais um projeto constitutivo. Para entender-se melhor esta tendência plural e translacional torna-se inevitável analisar o sentido e o funcionamento da heteronímia. A ideia do estudo é debater o fenômeno como uma proposta literária radical que, assentando na experiência da dissolução irremediável do real, passa a simular não a realidade, mas a ficção convertendo-se em literatura no sentido de uma rede de obras de autores nem existentes nem inexistentes. Como literatura no sentido tanto qualitativo como quantitativo, a heteronímia envolve passagens interculturais e tende, até, a transgredir seu próprio limite, a língua.
\end{abstract}

Palavras-chave: Heteronímia. Tradução heteronímica e heteronímia translacional. Plurilinguismo e outramento linguístico.

* Mestrado em História, Política Econômica e Romanística, Universidade de Freiburg e Universidade de Lisboa. Doutorado em Romanística (Português e Espanhol), Universidade de Freiburg. Pós-Doutorado (Habilitation), Universidade de Hamburgo. Cátedra de Estudos Interamericanos e Estudos Romanísticos na Universidade de Bielefeld. Professor convidado na Universidade Guadalajara, México. E-mail: joachim.michael@uni-bielefeld.de 


\title{
THE HETERONYMY OF FERNANDO PESSOA: MULTILINGUAL AND TRANSLATIONAL LITERATURE
}

\begin{abstract}
Fernando Pessoa is considered one of the most important Portuguese poets, but he was at the same time a great English poet. Proceeding on this observation, the present article proposes to discuss the function of languages, of their differences and of the interlingual passages in the work of Pessoa. This question, nonetheless, involves the problem of the heteronymic writing, as some heteronyms were foreigners and wrote in English and French, others were Portuguese and wrote in Portuguese, some translated into English, others translated into Portuguese, some divulged foreign literary works with essays in Portugal, others did the same in England. As a matter of fact, heteronymy founds in the transgressions of linguistic and cultural boundaries a constitutive project. In order to better understand this pluralistic and translational tendency it seems inevitable to analyze the meaning and the ways of functioning of the heteronymy. The idea of the study is to debate the phenomenon as a radical literary proposal that, on the basis of the experience of the dissolution irremediable of the real, simulates not reality but fiction. Heteronymy constitutes literature in the sense of a web of works of authors that neither exist nor don't exist. As literature in both a qualitative and a quantitative sense, heteronymy involves intercultural passages and tends even to transgress its own limit: its language.
\end{abstract}

Keywords: Heteronymy. Heteronymic translation and translational heteronymy. Multilingualism and linguistic alterity.

\section{A dissolução de Pessoa em literatura}

A escrita plurilíngue e translacional de Fernando Pessoa não pode ser concebida fora do contexto da heteronímia. Parece, portanto, necessário, rever este contexto antes de abordar a questão da passagem entre as línguas e entre as culturas, a qual - essa é a proposta do presente estudo - constitui uma tendência inerente à heteronímia e encontra nela função e sentido.

A heteronímia não se restringe aos três heterônimos (principais) e ao assim chamado ortônimo. Ela desdobra-se também na abundância de heterônimos considerados "menores": os semi-he- 
terônimos, os sub-heterônimos, os pré-heterônimos, os 'quase'-heterônimos, os para-heterônimos e os proto-heterônimos etc. Evidentemente, a figuras como Antonio Mora, Carlos Otto ou Alexander Search a qualidade de heterônimo por vezes é negada sendo definidos como "personagens literárias" (LOPES, 1990a, p. 162-3). Pessoa mesmo chega a fazer esta distinção ${ }^{1}$, porém também fala de "personalidades literárias" ${ }^{2}$. A distinção parece ter a função de assinalar que Alberto Caeiro, Ricardo Reis e Álvaro de Campos têm mais autonomia e são mais completos e mais criadores. O que caracteriza todas estas figuras, no entanto, é que não existem simplesmente em textos literários como personagens ou narradores senão que produzem-nos - sem que Fernando Pessoa possa assumir a autoria destas criações. Certamente, Caeiro, Reis e Campos têm uma obra e uma vida mais vasta e abrangente, e algumas das assim chamadas "personagens literárias" têm sua obra apenas projetada. Isto é, seus textos foram anunciados, mas nunca chegaram a ser escritos. Muitos têm uma obra que consiste apenas de alguns fragmentos, poemas ou textos breves, mas não obstante com assinatura própria. Ou seja, os três heterônimos principais são bem mais complexos que os outros, mas a diferença é, fundamentalmente, de ordem quantitativa e não qualitativa. Além do mais, no texto mais célebre de Pessoa sobre a gênese dos heterônimos, na carta a Adolfo Casais Monteiro de 1935, Pessoa não distingue entre essas personalidades e não reserva o termo "heterônimos" a Caeiro, Reis e Campos (cf. PESSOA, 1986a, p. 227). Naquela carta, Pessoa insiste sistematicamente em que os heterônimos não são seus. Segundo Pessoa, os heterônimos apareceram-lhe. Ele conheceu estas personalidades dentro dele mesmo.

Graduei as influências, conheci as amizades, ouvi, dentro de mim, as discussões e as divergências de critérios, e em tudo isto me parece que fui eu, criador de tudo, o menos que ali houve. Parece que tudo se passou independentemente de mim. (PESSOA, 1986a, p. 228) 
Pessoa, em outras palavras, faz questão de negar a autoria daquilo que ele chama heterônimo. Em consequência, ele desconstrói-se como sujeito criador que antecede o resultado de sua criação. Ele, em outras palavras, destrói o conceito de literatura que se fundamenta no conceito de autor porque converte a própria categoria de autor em objeto de ficção. Nada expressa melhor esta revolução literária que o comentário que faz na carta a Monteiro sobre Alberto Caeiro: "Desculpe-me o absurdo da frase: aparecera em mim o meu mestre. Foi essa a sensação imediata que tive." (PESSOA, 1986a, p. 228)

Ora, o resultado de uma criação literária, um produto, não pode sobrepassar o criador. $\mathrm{O}$ autor-sujeito não pode ser inferior ao que cria e assumir uma posição de discípulo. A obra depende do autor. Mas Pessoa, ao ficcionalizar o autor, mostra que por detrás dele já não se encontra um eu soberano do qual emana a criação artística. Caeiro, Reis, Campos e os outros são autores, escrevem, criam, produzem cada um uma obra literária, sim, mas por detrás de seus textos e nomes não se encontra nada, nenhum eu existente. A heteronímia, portanto, mostra que o autor real é dispensável na literatura, ou que se trata de uma categoria esvaziada. Ela mostra, também, que por detrás daquilo que conhecemos por "Fernando Pessoa" também não se encontra nenhum eu coerente, consistente e idêntico consigo mesmo. Tudo o que se acha é um eu fragmentado que convive com muitos outros e que, como sabemos, nunca se encontra a não ser quando é outro. Fernando Pessoa, enfim, não é real. Em última consequência, é tão heterônimo quanto os outros.

Qual é o sentido, vamos perguntar-nos, desta "pulverização" do eu e da "despersonalização" de que fala o "semi-heterônimo" Bernardo Soares (1990)? Obviamente, as consequências do desmantelamento da categoria do autor são muito abrangentes, já que desvincula a literatura de uma vez por todas daquilo que consideramos ser a realidade. No fingimento literário, o conceito do real deixa de ter utilidade. A literatura não se desprende necessariamente do eu, mas ela passa a duvidar e até a negar que o eu criador seja um eu realmente existente. O eu seria, então, descartável? Não de 
todo - este eu vazio, não real cumpre a função enunciativa da fala poética já que esta não exige que o eu enunciador de fato exista. De acordo com Pessoa, a fala poética até revoga a existência factual do eu. O próprio discurso lírico insiste repetidamente na corrosão do eu que se refugia em estados inconscientes onde se dispersa por completo. Confira-se, por exemplo, a primeira estrofe de um poema de Pessoa escrito em 1923.

Sonho. Não sei quem sou neste momento.

Durmo sentindo-me. Na hora calma

Meu pensamento esquece o pensamento

Minha alma não tem alma.

[...] (PESSOA, 1986b, p. 88)

Com o questionamento radical da realidade, Pessoa não só definiu um dos principais temas da modernidade e de todo o século. Ao mesmo tempo, e isto parece ainda mais significativo, ele converteu este problema filosófico em prática poética. Se a fala poética categoricamente remonta a um eu abstrato que prescinde de toda origem, esse eu não foge e não pode fugir ao fingimento. Então não somente o eu enunciador finge, senão que aquele eu que finge acaba por ser fingido. O assombroso da obra de Pessoa não está, portanto, em demonstrar (constantemente) em que o poeta finge senão em que ele finge a ficção. Conforme escreve Ricardo Reis, num poema de 1932, aludindo à noção barroca da vanidade do homem e da nulidade de sua existência, "somos contos contando contos, nada" (REIS, 1991, p. 140).

No fundo, o que a heteronímia põe de relevo é que, em termos literários, da mesma forma como o conceito da realidade deixa de ter sentido, igualmente o da ficção perde seu significado. ${ }^{3}$ Isto quer dizer que à literatura corresponde um status ontológico à parte que não assenta na oposição realidade-ficção. Pessoa, em outras palavras, não agregou à literatura um outro eu que de diversas maneiras finge o que "deveras sente", senão muitos eus fictícios e fin- 
gidores. ${ }^{4}$ Ou seja, se num sentido quantitativo, a literatura se constitui de um conjunto de autores e suas obras, Pessoa passou a criar toda uma literatura, já que a heteronímia apresenta uma multitude de eus que se expressam - ou melhor: que debatem o esvaziamento da expressão poética. O poeta ele mesmo sugere esta percepção da heteronímia como um agrupamento de poetas distintos, cada um com suas obras. Em um fragmento intitulado "Aspectos", que Pessoa destinava a ser um "prefácio geral" a um livro que daria a conhecer as obras dos heterônimos, ele escreve:

Tornando-me assim, pelo menos um louco que sonha alto, pelo mais, não só um escritor, mas toda uma literatura, quando não contribuísse para me divertir, o que para mim já era bastante, contribuo talvez para engrandecer o universo, porque quem, morrendo, deixa escrito um verso belo deixou mais ricos os céus e a terra e mais emotivamente misteriosa a razão de haver estrelas e gente. (PESSOA, 2007, p. 145)

A personalidade - inexistente - de Pessoa converte-se não só em outros senão em outros que escrevem. O que está em jogo é uma proposta de escrita literária radicalmente plural.

Com uma tal falta de literatura, como há hoje, que pode um homem de génio fazer senão converter-se, ele só, em uma literatura? Com uma tal falta de gente coexistível, como há hoje, que pode um homem de sensibilidade fazer senão inventar os seus amigos, ou, quando menos, os seus companheiros de espírito? (PESSOA, 2007, p. 145)

Se a realidade se desintegra em facetas isoladas e contraditórias, cada ponto de vista é válido - desde que seja fragmentário. Desta forma, as escritas heteronímicas ficcionalizam toda uma literatura 
composta de autores e obras que se correspondem, se diferenciam, se contradizem, mas sempre se relacionam de uma maneira ou de outra uns aos outros. Cada autor heteronímico escreve sobre "aspectos" daquilo que, no fundo, representa não a realidade mas sim o desaparecimento desta. Numa outra carta, sem data, Pessoa explica seu conceito de literatura: a literatura, como toda arte, é necessariamente contraditória:

Ao mesmo tempo que [a literatura] interpreta uma epocha, reage contra ela. [...] Assim, a arte (e sobretudo a litteratura) expressão intellectual das sociedades, tem o fim de ao mesmo tempo exprimir as suas tendencias occultas e de as contrariar, ordenando-as. (PESSOA apud LOPES, 1990a, p. 122)

A literatura, portanto, aparece como um conjunto heterogêneo que alberga "aspectos" diversos, pontos de vista contrários e estratégias opostas, tal como a tradição e a ruptura, a decadência e a renovação, o nacionalismo e o antinacionalismo, por exemplo. Sem dúvida, a pluralidade surge como um conceito chave. Tanto Fernando Pessoa como alguns (outros) heterônimos dão expressão à tendência plural do eu. É impossível não pensar em Álvaro de Campos e sua ode "A passagem das horas" que principia com os seguintes célebres versos:

Sentir tudo de todas as maneiras,

Viver tudo de todos os lados,

Ser a mesma cousa de todos os modos possíveis ao mesmo tempo,

Realizar em si toda a humanidade de todos os momentos

Num só momento difuso, profuso, completo e longínquo.

[...] (PESSOA, 1992a, p. 94) 
Ou seja, cada heterônimo, incluído Fernando Pessoa, escreve sobre a excentricidade do eu, sobre a não identidade do eu com ele mesmo, enfim, sobre a insuficiência do conceito já que um eu que é outro não pode ser o que pretende. Um eu que se multiplica acaba por dispersar-se, como observa o eu lírico em "A passagem das horas" (Álvaro de Campos):

[...]

Multipliquei-me para me sentir,

Para me sentir, precisei sentir tudo,

Transbordei, não fiz senão extravasar-me,

Despi-me, entreguei-me,

E há em cada canto da minha alma um altar a um deus

diferente.

[...] (PESSOA, 1992a, p. 96)

A consequência da multiplicação do eu é o plural dos eus - e o fim do eu em singular. É exatamente o que propõe a heteronímia. Mas em vez de simplesmente escrever sobre o eu múltiplo, ela transforma o discurso moderno sobre a multiplicidade do eu em prática poética multiplicando os eus que escrevem. ${ }^{5}$

\section{O plurilinguismo}

Em um poema de Fernando Pessoa, o eu lírico se define como uma "anthologia":

Eu sou uma anthologia.

Screvo tam diversamente

Que, pouca ou muita valia

Dos poemas, ninguem diria

Que o poeta é um somente.

(PESSOA apud LOPES, 1990b, p. 116) 
Ora, uma escrita literária sem origem (autêntico) transgride também os limites da língua. Ela já não se confina num só idioma. É sabido que as intensas reflexões de Pessoa sobre a língua portuguesa revelam que este idioma tem uma importância especial para ele. A ideia do Quinto Império, por exemplo, em Pessoa não é política nem religiosa, mas visa um império espiritual modelado pela língua portuguesa (PESSOA apud LOPES, 1993. p. 240). Discerne-se uma opção pelo português e/ou por Portugal na vida de Fernando Pessoa e de alguns dos heterônimos que não são portugueses, como Charles Robert Anon, os irmãos Alexander e Charles James Search e outros (cf. LOPES, 1990a, p. 131). A razão da superioridade da língua portuguesa está - segundo Pessoa - em que ela se presta especialmente à articulação dos sentimentos e à expressão individual. Por isto, ela aparece como a "lingua literaria e particular" (PESSOA apud LOPES, 1993, p. 154-5).

É sintomático, contudo, que justamente aquele fragmento que destaca as qualidades da língua portuguesa seja escrito em duas línguas: português e inglês. Ele é intitulado "Babel: or the Future of Speech". Paradoxalmente, a ideia principal deste fragmento é o elogio do bilinguismo: "A real man cannot be, with pleasure and profit anything more than bilingual." (PESSOA apud LOPES, 1993, p. 154)

Pessoa, neste texto, defende um pragmatismo que reconhece que o inglês é a língua franca em nível internacional. Mas não só isso, o inglês apresenta-se como meio de comunicação linguística por excelência: o idioma impõe-se como "lingua scientifica e geral". Portanto, é preciso usar as duas línguas, português e inglês, tal como o põe em prática o próprio fragmento: "Para o que queremos aprender leremos inglez; para o que queremos sentir, portuguez. Para o que queremos ensinar, fallaremos inglez; portuguez para o que queremos dizer."(PESSOA apud LOPES, 1993, p. 155)

Em conclusão, apesar de seus méritos, o português não pode ser tudo: "Concentremo-nos no portuguez, como elle se houvesse de ser tudo; não esqueçamos, porém que elle pode não ser mais que metade de tudo." (PESSOA apud LOPES, 1993, p. 154) 
Para Fernando Pessoa, a língua portuguesa de fato não foi tudo. Quanto à sua "própria" obra (ortônima), ele escreveu em português e em inglês durante toda a sua vida. Poder-se-ia até considerar Pessoa um poeta em português e em inglês (TERLINDEN, 1990, p. 13). ${ }^{6}$ Não parece mera coincidência que - ao lado de alguns poemas aparecidos separadamente em revistas literárias - o escritor tenha publicado somente uma obra em português em vida (Mensagem, de 1934) e quatro em inglês: 35 Sonnets, Antinous, Inscriptions e Epithalamium, lançados em 1918 e 1921 em Lisboa. Além destas coletâneas escreveu em inglês entre 1911-1917 outro livro de poesia intitulado The Mad Fidler assim como uma vasta poesia solta, diversos ensaios, fragmentos e um guia turístico sobre a cidade de Lisboa (Lisbon: What the Tourist Should See, de 1925). ${ }^{7}$ A divulgação de sua própria obra inglesa parece ter sido uma grande inquietude. Tudo leva a crer que ele queria ser reconhecido também como autor inglês. Sabe-se, por exemplo, que tentou publicar The Mad Fidler, já que existe uma carta de um editor inglês em que este rejeita o propósito (TERLINDEN, 1990, p. 1416). Pessoa também escrevia em francês (LOPES, 1990a, p. 106).

Mas o poeta não somente se "dividia" entre as línguas senão também se dedicava à passagem translacional entre uma e outra. Um dos dados biográficos mais conhecidos é sua atividade profissional como correspondente e tradutor comercial. Pessoa, porém, era também um tradutor literário. Ele traduziu diversas obras literárias para o português e para o inglês, sempre de diversas línguas. Pessoa queria dar a conhecer clássicos estrangeiros na língua portuguesa. Para isto traduziu autores como Luís de Góngora, Francisco de Quevedo, William Wordsworth, Elizabeth Browning, Garcilaso de la Vega, Shelley, Coleridge, Edgar Allan Poe. Um grande projeto foi a tradução dos clássicos da literatura universal ao português. Para este fim, em 1907, inclusive monta uma editora, a Empresa Íbis, que, no entanto, faliu rapidamente (LOPES, 1990a, p. 112-3). Pessoa, no entanto, não desistiu de seu propósito, conforme prova uma carta de 1923 ao editor João de Castro (Cf. LOPES, 1993, p. 222-3). Como mostra a carta, já estavam 
avançados seus planos "de fazer conhecidos do publico portuguez, em selectas reduzidas, os principaes poetas e prosadores estrangeiros de que elle [o público português] pouco mais conhece que os nomes". O poeta previa a publicação de "uma collecção de pequenos livros, uniformes no formato, no aspecto e no preço". Conforme Pessoa sublinha, ele não poderia sozinho, encarregar-se desta enorme tarefa. Mas ele compromete-se a traduzir uma grande parte. Ele encarrega-se de traduzir "as principaes obras" de William Shakespeare, e, como acrescenta, a versão portuguesa de A tormenta já está pronta, só faltando a redação final. No mesmo estado se encontram os "Principaes poemas" de Edgar Allan Poe. "Adeantada", escreve, está a tradução dos "Principaes poemas" de Robert Browning, assim como de Hamlet de Shakespeare. Além disto, anuncia verter para o português os grandes poetas ingleses oitocentistas, isto é, as principais obras "de Wordsworth, de Coleridge, de Mathew Arnold, de Shelley, de Keats, e, em volumes de conjuncto, dos poetas menores da Restauração ingleza (Sedley, Suckling, Lovelace, etc.) e da epocha victoriana em seu fim (O'Shaughmsay, Dowson, Lionel Johnson, e outros)" (PESSOA apud LOPES, 1993, p. 222-3) .

Da mesma forma, como Pessoa queria levar os portugueses a conhecer os clássicos estrangeiros, ele também queria levar o público estrangeiro a conhecer os clássicos portugueses. Entre as obras portuguesas que ele queria publicar em inglês, também estão as dos heterônimos. Existem traduções de Pessoa dos poemas "Opiário" e "Ode marítima" de Álvaro de Campos, mas que estão incompletas. ${ }^{9}$

\section{A heteronímia translacional}

Fernando Pessoa, não obstante, não foi o único (heterônimo) que traduzia e escrevia em outras línguas. Uma série de heterônimos menores ou escreviam em inglês ou em francês ou traduziam ou faziam as duas coisas. Alexander Search é o principal autor 
inglês entre eles. Ele escreveu 117 poemas, datados entre 1903 e 1909 (TERLINDEN, 1990, p. 133). O principal autor francês é Jean Seul. Dele encontraram-se três ensaios (cf. LOPES, 1990b, p. 196-206). Outros heterônimos apenas traduziam, como o irmão de Alexander, Charles James Search de quem existe uma lista de obras portuguesas a traduzir para o inglês. Entre elas estão os sonetos de Antero de Quental, uma seleção de sonetos de Luís de Camões, uma seleção de obras de Guerra Junqueiro e de Almeida Garrett assim como o romance $O$ Mandarim de Eça de Queiroz, entre outros (CH. SEARCH apud LOPES, 1990b, p. 196-7). Vicente Guedes é outro heterônimo-tradutor. Ele aparece numa lista de obras traduzidas que a empresa editorial Ibis deveria publicar. Nesta lista, consta de que dele serão as traduções das tragédias de Ésquilo, de Caim de Lord Byron e de Prometheu liberto de Percy B. Shelley (GUEDES apud LOPES, 1990b, p. 229). Guedes também traduzia outros heterônimos, como Horace James Faber (LOPES, 1990a, p. 114). O mesmo heterônimo era, também, escritor e previa publicar pelo menos três contos na editora Ibis (idem).

É verdade que as traduções entre os heterônimos na maioria dos casos apenas se anunciaram, mas não foram efetuadas. Ou seja, efetivamente, os heterônimos - com exceção de Pessoa ele mesmo - na prática não produziam traduções. É possível que simplesmente tenha faltado tempo para realizar os inúmeros projetos que se encontram em forma de rascunho no espólio. Prova da vontade de traduzir os heterônimos são, por exemplo, as apresentações de Alberto Caeiro e Álvaro de Campos pelo mini-heterônimo I.I. Crosse em inglês (LOPES, 1990b, p. 235-7). Trata-se de pequenas introduções aos dois autores que se dirigem a um público que lê em inglês, o que cria a expectativa de que logo se apresentem suas obras, ou pelo menos parte delas, neste idioma. Veja-se como Crosse destaca em particular a excepcionalidade artística e cultura de Caeiro:

Here at last [...] is a work that appeals to me not as man of to-day (no work could be further removed from every 
known current of contemporary art), not as an Englishman (no work could be less English), but indeed as a man of mankind. (I.I. CROSSE apud Lopes, 1990b, p. 235)

Acrescente-se que I.I. Crosse provavelmente teve um irmão, Thomas Crosse. Thomas, segundo Teresa Rita Lopes, era ensaísta e se empenhava em divulgar a literatura portuguesa na Inglaterra. Existe um rascunho em inglês de um texto sobre a literatura portuguesa do qual consta que pretendia escrever sobre uma série de poetas portugueses "injustamente desconhecidos". Entre eles estão Antero de Quental, Guerra Junqueiro, Cesário Verde, os “decadentes e pessimistas" e também os "sensacionistas", sendo os últimos um grupo de vanguardistas que se constitui, em grande, mas não unicamente, de Pessoa e dos (outros) heterônimos (CROSSE apud LOPES, 1990b, p. 233; cf. LOPES, 1990a, p. 126-7). Segundo Richard Zenith, era também tradutor e ia traduzir a obra de Alberto Caeiro. De Thomas, existe um "Prefácio do tradutor" aos poemas de Caeiro em versão inglesa, que, aliás, inexistem. Sendo tradutor ou não, Thomas Crosse escreveu um belo estudo sobre a poética daquele heterônimo. Nele, a intenção de promover a literatura heteronímica (não só de Caeiro senão também dos "discípulos" Ricardo Reis e Álvaro de Campos) entre o público inglês é muito clara. Caeiro é comparado, ou melhor: posto em relação a Walt Whitman, e, ao mesmo tempo, Crosse enfatiza a originalidade do poeta heteronímico, destacando sua novidade radical e a ruptura que representa para com a tradição literária. A tradução, ou seja, o prefácio, apresenta-se como uma "revelação":

In placing before the English-reading public my translation of these poems, I do so with the full confidence that I am making a revelation. I claim, in all confidence, that I am putting before Englishmen the most original poetry that our young century has yet produced - a poetry so fresh, so new, untainted to such a degree by any kind of conventional attitude, that the words a Portuguese friend said to 
me, when speaking of these very poems, are more than justified. "Every time I read them," he said, "I cannot bring myself to believe that they have been written. It is so impossible an achievement!" And so much impossible, that it is of the simplest, most natural and most spontaneous kind. (CROSSE, 2007, p. 155)

Mesmo que os projetos de tradução heteronímica somente tenham sido realizados muito fragmentariamente, está muito claro que a heteronímia não se confinava nem ao campo literário de Portugal nem à língua portuguesa. A existência dos heterônimos que escreviam em inglês ou em francês, dos que traduziam para o português ou para o inglês, a obra inglesa do próprio Pessoa e, ainda, suas traduções confirmam a tendência da heteronímia de transgredir os limites da cultura e da língua. De fato, a heteronímia nem se restringe somente ao discurso propriamente literário e se estende até à escrita filosófica, como mostra o heterônimo Antonio Mora, o teórico do "neopaganismo" (cf. LOPES, 1990a, p. 197-213). Precisamente no campo do discurso não literário é onde a heteronímia procede a transgressão dos limites culturais e linguísticos. Os irmãos Crosse são exemplos de que não bastaria traduzir as obras literárias para dar a conhecê-las numa outra língua senão que era preciso também apresentá-las e comentá-las nesta língua. Era preciso explicá-las, inseri-las num contexto, estabelecer referências - enfim, era necessário facilitar a recepção. No fundo, o que estes heterônimos fazem é já antecipar esta recepção sendo eles ingleses, que como tais introduzem seus conterrâneos na poesia heteronímica portuguesa.

A tradução em Pessoa não pode ser, somente, uma prática, parte da dinâmica da escrita heteronímica. Nesta, a transgressão linguística, como se nota, é substancial. É quase inevitável uma reflexão (no caso de Pessoa: reflexões) sobre a própria tradução e, também, sobre a natureza das línguas e seus limites. A princípio levanta-se uma questão: por que o escritor se compromete com a tradução se ele já escreve em pelo menos três línguas e se surgem heterônimos anglófonos e francófonos? Poderíamos pensar que 
as produções literárias em outras línguas dispensariam o esforço translacional, pelo menos em parte e para os mencionados idiomas. Mas não é assim. Num fragmento ensaístico, Pessoa valoriza a tradução como uma espécie de intermediação no processo literário, porque ela possibilita a circulação literária: "Entendamo-nos bem. Ninguem pode ler tudo, sequer sobre um só assunto." (PESSOA apud LOPES, 1993, p. 219)

Neste sentido, Pessoa defende explicitamente o processo intermediário de citações "em segunda mão" e de traduções de traduções: "É, pois necessário, muitas vezes, citar em segunda-mão, quando não ainda mais translatamente" (PESSOA apud LOPES, 1993, p. 219)

A tradução facilita a leitura: "É preferível citar em portuguez" - segundo Pessoa - "até para conveniencia do leitor" (PESSOA apud LOPES, 1993, p. 219). Evidentemente, o autor não deixa de formular suas ressalvas que consistem em preservar o sentido e o ritmo do texto traduzido e retraduzido. A tradução ajuda a divulgação da literatura estrangeira e assim ela promove o intercambio entre as literaturas. O patriotismo de Pessoa parece ter sido um patriotismo linguístico: ele estimava a língua portuguesa porque a considerava ao mesmo tempo complexa e maleável (PESSOA apud LOPES, 1993, p. 220) e por diversos motivos previa um grande futuro para ela. Mas como já mencionei, esta fé na língua portuguesa não excluía outros idiomas. O patriotismo linguístico não poderia reintroduzir uma noção de identidade, desta vez a nível coletivo. Lembro a "primeira regra" do sensacionismo - aquele movimento que Pessoa e a grande parte dos (outros) heterônimos propagavam direta ou indiretamente como programa literário (de vanguarda) que - é difícil não reconhecê-lo - sintetizava a assombrosa proposta da literatura heteronímica. A "primeira regra" do sensacionismo, portanto, é:

[...] sentir tudo de todas as maneiras. Abolir o dogma da personalidade: cada um deve ser muitos. A arte é aspiração do indivíduo a ser o universo. O universo é uma cousa 
imaginada: a obra de arte é um producto de imaginação. (PESSOA apud LOPES, 1993, p. 266)

Um sensacionista, portanto, não é, mas são. Não faria sentido que se contentasse com uma língua se ele extingue toda ideia de centro e unidade. A língua, nem a portuguesa, não poderia despertar um novo sentimento de pertinência. Pelo contrário, as línguas constituem uma nova etapa do outramento. Pessoa torna-se diverso também em nível linguístico.

Enfim, não é somente o aspecto pragmático que interessava Pessoa na tradução. É sobretudo a dimensão estética da língua. Não se pode escrever igual em línguas diferentes. Numa carta de 1934, por exemplo, Pessoa comenta que só em inglês consegue expressar-se de maneira simples. Em português, contudo, não lograria “escrever com simplicidade" (LOPES, 1993, p. 157). A dimensão estética é própria a cada língua - mas não necessariamente ao individuo. Isso significa que cada língua constitui um ordenamento espiritual particular. A língua se impõe ao indivíduo - não é ele que possa dispor dela de maneira soberana. Entre elas, as línguas são mais ou menos incompatíveis. As distâncias entre elas variam. Mas sempre se abre um interstício entre as línguas. E nestas zonas limítrofes e interlinguísticas opera Pessoa. Num outro fragmento sobre a tradução - escrito, aliás, em inglês - ele defende que a tradução só tem sentido quando as línguas são muito diferentes:

The only interest in translations is when they are difficult, that is to say, either from one language into a widely different one, or from a very complicated poem though into a closely allied language. There is no fun in translating, say, Spanish and Portuguese. (PESSOA apud LOPES, 1993, p. 220)

Neste mesmo fragmento, o escritor, porém, vai mais longe. Ele equipara a tradução com o plagiato e com a paródia: 
[...] a translation is only a plagiarism in the author's name. A History of Parodies would complete the series, for a translation is a serious parody in another language. (PESSOA apud LOPES, 1993, p. 220)

O que Pessoa está propondo é que a tradução é uma deslocação, uma transmutação de um texto em que ele no entanto preserva características elementares. O texto, no final do processo, ainda é o mesmo e ao mesmo tempo já é outro - nisto se assemelha a tradução ao plagiato e à paródia

In both cases, there is adaptation to the spirit of the author for a purpose which the author did not have; in one case the purpose is humour, where the author was serious, in the other one language when the author wrote in another. (PESSOA apud LOPES, 1993, p. 220)

Como se vê, para Pessoa não há dúvida de que tradução necessariamente é modificação e infidelidade. A ideia é que a incompatibilidade entre as línguas não permite transladar um texto de um idioma a outro sem que ele seja afetado por essa passagem. Por este motivo o escritor propõe que se traduzam os textos não só para outras línguas senão eventualmente também para o idioma em que foram escritos: "But there can be no doubt that many poems - even many great poe$m s$ - would gain by being translated into the very language they were written in" (PESSOA apud LOPES, 1993, p. 220)

A noção de que se possa legitimamente intervir num poema, num texto mesmo de um grande autor com a finalidade de melhorá-lo mostra quão fraco é para Pessoa o conceito de autoria. A pessoa do autor, o artista, não importa na arte, o que importa é somente a arte:

This brings up the problem as to whether it is art or the artist that matters, the individual or the product. If it be the final result that matters and that shall give delight, then we 
are justified in taking a famous poet's all but perfect poem, and, in the light of the criticism of another age, making it perfect by excision, subsitution or addition. (PESSOA apud LOPES, 1993, p. 220)

Enfim, a função da tradução na heteronímia é multifacética. Junto com as críticas, resenhas e introduções acerca das obras produzidas pelos heterônimos, tornam mais completa e mais complexa o tecido literário formado pela heteronímia. A divisão de trabalho entre os heterônimos - alguns só traduzem, alguns só opinam ou refletem - reforça o caráter da heteronímia como literatura no sentido de uma rede de textos heterogêneos e de variados gêneros que das mais diversas maneiras se relacionam e se encadeiam. Mas uma literatura ainda é pouco! As ramificações da heteronímia se estendem para além das fronteiras linguísticas. Através das traduções para o português se incorporam outras literaturas. A través das traduções do português e por meio da escrita plurilíngue os heterônimos e o sensacionismo se devem divulgar também fora de Portugal - pelo menos essa parece ter sido a ideia. Mas ao traduzir e ao escrever em outras línguas, os heterônimos, que já são outros desde o princípio, tornam-se uma vez mais outros e assumem a diferença daquilo que se poderia considerar o único que é realmente e propriamente deles: a língua.

\section{Notas}

1. Carta em que Pessoa introduz o termo "personagens literárias".

2. “Carta de Fernando Pessoa para João Gaspar Simões”, de 28/06/1932. 
3. Bernardo Soares, no Livro do Desassossego, antecipa o que a fenomenologia explicaria mais tarde: realidade e consciência não se opõem, com o mundo - externo - estando de um lado, e a consciência - igual a um aparato interno - estando do outro, e buscando a consciência vencer a distancia epistemológica entre ambos. Pelo contrário, fenomenologicamente, as duas partes - mundo e consciência - estão intimamente entrelaçados, constituindo um ao outro, dependo um do outro e formando um ato perceptivo. Conclui-se que a realidade não antecede a consciência, senão surge na percepção humana (Cf. WALDENFELS, 1980, p. 12). Neste sentido entende-se Bernardo Soares quando pontualiza num fragmento intitulado "Encolher de ombros" que o que denominamos realidade não é autônomo se não, pelo contrário, uma espécie de invenção nossa: "Manufacturamos realidades" (SOARES, 1986, p. 58).

4. Tome-se o exemplo do (sub-)heterônimo Vicente Guedes. Ele é tradutor, poeta e autor de um diário. Numa apresentação de sua obra lemos sobre o último: "Este livro é a biografia de alguém que nunca teve vida." Que a heteronímia se posiciona muito além da oposição real - fictício mostra o seguinte comentário, ainda ao diário, que, aliás, resume a literatura heteronímica: "Este livro não é d'elle: é elle." (PESSOA apud LOPES, 1990b, p. 228). Do diário existe pelo menos um fragmento (cf. LOPES, 1990b, p. 230).

5. A heteronímia, nesta perspectiva, surge-nos como a verdadeira poética/poesia moderna que reflete/promove aquilo que aparece como um dos signos sobressalientes da modernidade: a multitude. Walter Benjamin observou que na obra de Charles Baudelaire as multitudes constituem um tema central, já que são elas que marcam o fenômeno inédito da grande cidade. O que está em questão é a massa e a reconfiguração da vida urbana que se inicia com ela (cf. BENJAMIN, 1969a, p. 212-4). Em Pessoa e nos (outros) heterônimos, o tema da massa não parece ter grande relevância quantitativa. Mas a categoria da multitude e da multiplicação não se limita a aglomerações humanas nas ruas que determinam a experiência urbana do flâneur. Como mostra Benjamin, ela intervém de diversas maneiras na percepção sensorial humana formando um tipo de sensibilidade específica e particular marcada pelo excesso de estímulos provocados pela aceleração da vida urbana. Nesses choques instantâneos, Benjamin também destaca a mídia, sobretudo o cinema que somete o espectador a uma vertigem de imagens rápidas. Essas imagens são imagens técnicas que se reproduzem em grande número. A multiplicação da imagem a partir de sua reprodutibilidade técnica, por sua vez, transforma a arte que perde sua aura - a autenticidade fundada em sua unicidade. A massificação, em outras palavras invade a arte - não só a nível do discurso - senão a nível das condições de sua produção (cf. BENJAMIN, 1969b). Com outras premissas, sendo resultado do esvaziamento do real, a multiplicação reaparece em Pessoa, não só como tema senão como estrutura da criação artística. Bernardo Soares, no 
Livro do Desassossego, por exemplo escreve: "Criei-me eco e abismo, pensando. Multipliquei-me, aprofundando-me" (SOARES, 1986, p. 55). Num fragmento em inglês e sem data, não obstante, Pessoa até reflete explicitamente - e a sua maneira - o paradigma da multitude nas ruas da cidade grande. $\mathrm{O}$ eu-narrador apresenta-se como "homem da multidão" que busca submergir nas multidões urbanas, refugiando-se nelas: "I became a man of the crowd. [...] From night unto morn, and from morn unto night, I elbowed myself speedily through crowds, clinging affrightedly to whom I could. Many thought me a thief. But I pressed my body against their bodies as a child clings to its mother during a thunderstorm." Está claro que está em questão o eu moderno que já não se opõe às massas senão se sabe ou antes se quer homem de massa. De que tenta escapar este eu que prefere os choques físicos dos transeuntes à distância tranquila e contemplativa (que era a do flâneur)? A resposta que o trecho insinua é o fracasso deste eu integral e idêntico que se converteu em fonte de desamparo e desassossego: "I never trusted myself alone" (PESSOA apud LOPES, 1990b, p. 23).

6. No estudo de Anne Terlinden também se encontram referências - inevitáveis neste contexto - à biografia de Pessoa, nomeadamente à adolescência sul-africana (TERLINDEN, 1990, p. 13-7). Que a biografia, contudo, não é suficiente para explicar o bilinguismo do escritor é o propósito do presente trabalho.

7. A Poesia inglesa de Pessoa encontra-se publicada, entre outros, em dois volumes, editados e traduzidos por Luísa Freire (PESSOA, 2000). Para uma versão bilíngue de Lisbon: What the Tourist Should See, veja-se Pessoa (1992b). Os fragmentos e ensaios ingleses encontram-se em grande parte em Lopes (1990b) e Lopes (1993).

8. Sobre Pessoa como tradutor veja-se Saraiva (1996). Veja-se também o importante estudo de Vivina Figueiredo (2005) sobre a importância da tradução no poeta.

9. “Opiary" e "Naval Ode" se encontram em Lopes (1993, p. 212-4). 


\section{Referências}

BENJAMIN, Walter. Über einige Motive bei Baudelaire. In: . Illuminationen. Frankfurt am Main: Suhrkamp, 1969a. p. 201-45.

. Das Kunstwerk im Zeitalter seiner technischen Reproduzierbarkeit. In: Illuminationen. Frankfurt am Main: Suhrkamp, 1969b. p. 148-84.

CROSSE, Thomas. Translator's Preface. In: PESSOA, Fernando. Obra essencial: Prosa íntima e de autoconhecimento. Edição de Richard Zenith. Lisboa: Assírio \& Alvim, 2007. v. 5. p. 155-70.

FIGUEIREDO, Vivina Almeida Carreira de Campos. Fernando Pessoa e a tradução. Hermeneus: Revista de la Facultad de Traducción e Interpretación de Soria, n. 7, 2005. Disponível em: < http://recyt.fecyt.es/index.php/HS/article/ viewFile/6175/8005 > . Acesso em: 20/09/2012.

LOPES, Teresa Rita (Org.). Pessoa por conhecer I: Textos para um novo mapa. Lisboa: Estampa, 1990a.

(Org.). Pessoa por conhecer II: Roteiro para uma expedição. Lisboa: Estampa, 1990b.

(Org.). Pessoa inédito. Lisboa: Livros Horizonte, 1993.

PESSOA, Fernando. Carta a Adolfo Casais Monteiro de 13.01.1935. In:

Obra em prosa de Fernando Pessoa: Escritos íntimos, cartas e páginas autobiográficas. Introdução, organização e notas António Quadros. Lissabon: Europa - América, 1986a. p. 224-31.

. Poemas de Fernando Pessoa. Edição Isabel Pascoal. Lisboa: Editorial Comunicação, 1986b.

. Poemas de Álvaro de Campos. Edição de Cleonice Beradinelli. Lisboa: Imprensa Nacional - Casa da Moeda, 1992a. 
. Lisboa: O que o turista dever ver - What the Tourist should See. Tradução Maria Amélia Santos Gomes, Richard Zenith. Lisboa: Livros Horizonte, 1992b.

. Poesia inglesa. In: . Obras de Fernando Pessoa. Edição e tradução por Luísa Freire. Lisboa: Assírio \& Alvim, 2000. v. XI e XII.

. (2007): Aspectos - Prefácio geral. In: Obra essencial: Prosa íntima e de autoconhecimento. Edição Richard Zenith. Lisboa: Assírio \& Alvim, 2007. v. 5. p. $143-48$.

REIS, Ricardo. Poemas de Ricardo Reis. Edição de Manuel Gusmão. Lisboa: Editorial Comunicação, 1991.

SARAIVA, Arnaldo (Org.). Fernando Pessoa, poeta-tradutor de poetas: os poemas traduzidos e o respectivo original. [Porto]: Lello Editores, 1996.

SOARES, Bernardo. Livro do desassossego. Edição Maria Alzira Seixo. Lisboa: Editorial Comunicação, 1986.

. O manual do sonhador: os graus do sonho. In: LOPES, Teresa Rita. Pessoa por conhecer II: Roteiro para uma expedição. Lisboa: Estampa, 1990. p. 253-55.

TERLINDEN, Anne. Fernando Pessoa - The bilingual Portuguese poet: a Critical Study of “The mad fiddler”. Bruxelles: Publ. des Fac. Univ. Saint-Louis, 1990.

WALDENFELS, Bernhard. Der Spielraum des Verhaltens. Frankfurt/M.: Suhrkamp, 1980

Recebido em: 12/02/2014

Aceito em: 23/05/2014 